\title{
Studies of Preconcentration of Brilliant Green Dye on $\beta$-Cyclodextrin Epichlorohydrin Polymer
}

\author{
RUPINDER KAUR and USHA GUPTA* \\ Department of Chemistry, Punjabi University, Patiala, Punjab, India \\ ushagupta_doc@yahoo.co.in
}

Received 16 April 2013 / Accepted 7 May 2013

\begin{abstract}
A solid phase extraction method for the preconcentration of Brilliant Green (BG) dye at trace level using $\beta$-cyclodextrin polymer. The residual concentration of the dye solute was determined by spectrophotometric method. The effect of various parameters, such as the $\mathrm{pH}$, contact time, amount of adsorbent, sample volume etc. were observed and discussed. This method has been applied for the determination of Brilliant Green Dye in different food samples such as jelly, mouth freshener $e t c$.
\end{abstract}

Keywords: Brilliant green dye, $\beta$-Cyclodextrin epichlorohydrin polymer ( $\beta$-CDP), Preconcentration, Spectrophotometry

\section{Introduction}

For food industries, color is the first notable characteristic of a food. Colorants are often added to food to enhance its visual aesthetics and promote sales. Color additives reinforce the colors already present in the food and ensure its uniformity. Brilliant green dye has been used in fish farming industry for many decades because of its broad anti-microbial, anti-parasitic and antifungal spectrum, its high efficiency in the prevention and treatment of certain fish disease and its low cost. BG dye containing effluents are generated from textiles, printing and dyeing, paper, rubber, plastic industries, etc. proved by Mane et al. ${ }^{1}$. BG dye causes irritation to the gastrointestinal tract, respiratory tract; skin with redness and pain ${ }^{2}$; symptoms may include nausea, vomiting, diarrhea, coughing and shortness of breath and having carcinogenic and mutagenic effects ${ }^{3-4}$ that affect aquatic biota and also humans ${ }^{5}$. Different techniques are used for the separation and preconcentration of dyes in the solution. These include photocatalytic bleaching $^{6}$, gamma radiolysis ${ }^{7}$ and electrochemical removal ${ }^{8}$. Some methods are very costly and required the expert hands. So, spectrophotometry is widely used for the determination of dyes due to its higher sensitivity, low cost, low interference level and its excellent detection limits. So, brilliant green dye has been determined by spectrophotometric methods after preconcentration using $\beta$-CDP in food samples.

Supramoleculer complexes with $\beta$-cyclodextrin has been a very active research field in the past few years ${ }^{9,10} . \beta$ - cyclodextrin $(\beta$-CD) is a very stable oligosaccharide that is composed 
of seven glucose units linked with each other by $\alpha$-(1,4)-glycosidic linkage. It can form supramoleculer complexes with several organic compounds by incorporating them into their hydrophobic cavities. Two or more $\beta$-cyclodextrin covalently linked with each other are known as polymers. These $\beta$ - cyclodextrin polymer have been used for the preconcentration of various analytes $^{11-14}$. In the present work, $\beta$-cyclodextrin epichlorohydrin polymer $(\beta$-CDP) has been used as a solid support for the preconcentration of Brilliant green dye.

\section{Experimental}

A Shimadzu UV-1800 spectrophotometer (Shimadzu Ltd., Japan) equipped with the matched $10 \mathrm{~mm}$ quartz cells was used to measure absorbance. Digital century $\mathrm{pH}$-meter $\mathrm{C}_{\mathrm{p}}$ 901 with a combined glass electrode was used to carry out $\mathrm{pH}$ measurements. A thermostatic shaking water bath (Perfit India Ltd.) was used to carry out all the inclusive procedures.

\section{Reagents}

All chemicals used were of AnalR grade unless otherwise stated. Double distilled water was used throughout the experiment. Brilliant green dye solution was prepared by dissolving $0.482 \mathrm{~g}$ in $100 \mathrm{~mL}$ of double distilled water to give $0.01 \mathrm{M}$ standard stock solution and further diluted as and when required.

$40 \mathrm{~g}$ of $\beta-\mathrm{CD}, 10 \mathrm{~g}$ of soluble starch and $100 \mathrm{~mL}$ of $20 \%$ sodium hydroxide were added into a beaker. The mixture was vigorously stirred at $50-60{ }^{\circ} \mathrm{C}$ until the reactants dissolved. Total $60 \mathrm{~mL}$ of Epichlorohydrin was added drop wise into the solution and $\beta$-CDP was formed in $30 \mathrm{~min}$. Filtered with pressure through Buchner funnel and then washed with distilled water 5-6 times, the polymer was dried at $100{ }^{\circ} \mathrm{C}$ and then stored at room temperature in the desiccators for further use.

Buffer solution in the $\mathrm{pH}$ range of 2.0-3.5 were made by mixing equimolar solutions of hydrochloric acid/Sodium Acetate and buffer solutions in the $\mathrm{pH}$ range of 4.0-6.5 were made by mixing equimolar solutions of sodium acetate and acetic acid solutions in the different proportions While those in the $\mathrm{pH}$ range of 7.0-11.0 were made by mixing equimolar solutions of ammonia and ammonium chloride. The glass wares were washed with chromic acid and soaked in 5\% nitric acid and then cleaned with double distilled water before use and dried in an electric oven.

\section{Procedure}

$200 \mathrm{mg}$ of $\beta$-CDP and $2.5 \mathrm{~mL}$ of buffer solution ( $\mathrm{pH} 4.0$ ) were added to a $100 \mathrm{~mL}$ stoppered conical flask at room temperature. The mixture was allowed to stand for $5 \mathrm{~min} .3 \mathrm{~mL}$ of dye was added and made up to $90 \mathrm{~mL}$ with double distilled water. After the mixture was shaken in the thermostatic shaking water bath for $120 \mathrm{~min}$., $5.0 \mathrm{~mL}$ of supernatant solution was transferred into a $10 \mathrm{~mL}$ volumetric flask and the absorbance was measured using spectrophotometric method.

\section{Results and Discussion}

\section{Optimization of various parameters}

\section{Effect of $p H$}

The complexation of the dye with the polymer depends on the $\mathrm{pH}$ of the sample solution which was studied in the range of (1.0-7.0.) using different buffer solutions. As it can be seen in (Figure 1), \% uptake $(\geq 95)$ was obtained at $\mathrm{pH}$ 4.0. Therefore, the working $\mathrm{pH}$ was chosen as 4.0 for the subsequent studies. 


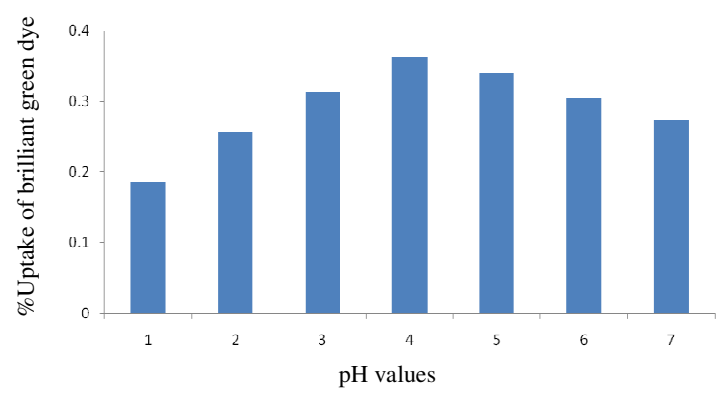

Figure 1. Effect of $\mathrm{pH}$ on the $\%$ uptake of the brilliant green dye by the polymer

\section{Effect of shaking time}

Shaking time is an important factor in determining the possibility of application of the $\beta$-CD polymer for the selective uptake of brilliant green dye. Different shaking time (ranging from 15 to $145 \mathrm{~min}$ ) were studied for the \% uptake of brilliant green dye by $\beta$-CD polymer. The results of $\%$ uptake of brilliant green dye vs. the shaking time show that the \% uptake of $(\geq 95 \%)$ was attained at $120 \mathrm{~min}$.(Figure 2). Therefore, the shaking time of $120 \mathrm{~min}$. was selected for further studies.

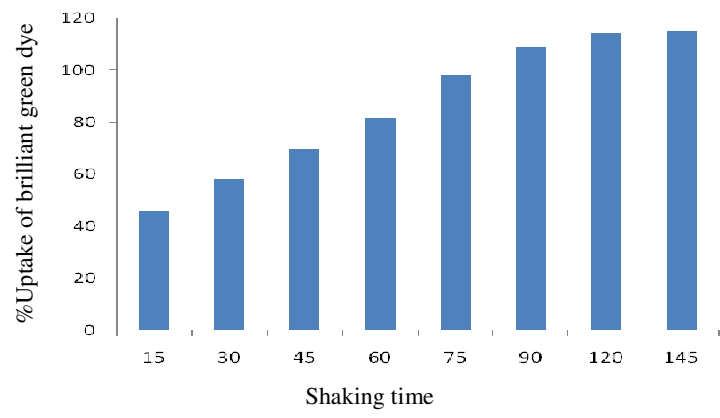

Figure 2. Effect of shaking time on the \% uptake of the brilliant green by the polymer

\section{Effect of sample volume}

Sample volume is an important factor in determining the possibility of application of polymer for the \% of uptake of brilliant green dye. For this purpose 15, 30, 45, 60, 90 and $120 \mathrm{~mL}$ of sample volumes were taken and uptake of brilliant green dye was studied (Figure 3). The maximum \% uptake $(\geq 95 \%)$ of brilliant green dye at sample volume of $90 \mathrm{~mL}$. Therefore, $90 \mathrm{~mL}$ of sample volume was used for the further studies.

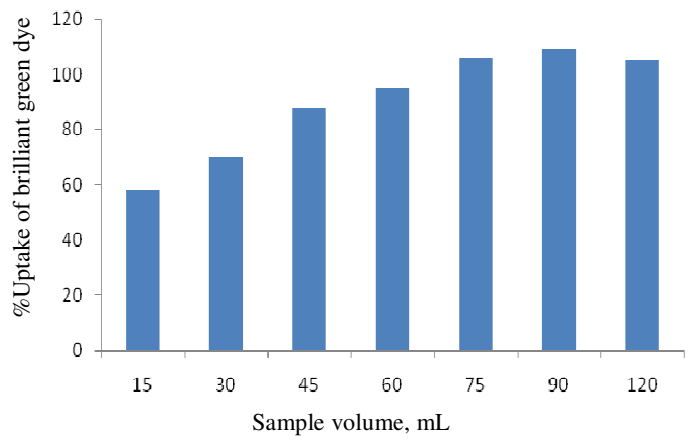

Figure 3. Effect of sample volume on the \% uptake of the brilliant green by the polymer 


\section{Effect of agitation speed}

Speed of shaking is the important factor in determining the possibility of application of polymer for the quantitative \%uptake of brilliant green dye. Different speed (ranging from 40 to 140 r.p.m) were studied for the $\%$ uptake of brilliant green dye by polymer. The results of \% uptake of brilliant green vs. agitation speed (Figure 4) shows that the \% uptake reach maximum $(\geq 95 \%)$ at 120 r.p.m. Therefore, the shaking speed of 120 r.p.m. was selected for the further studies.

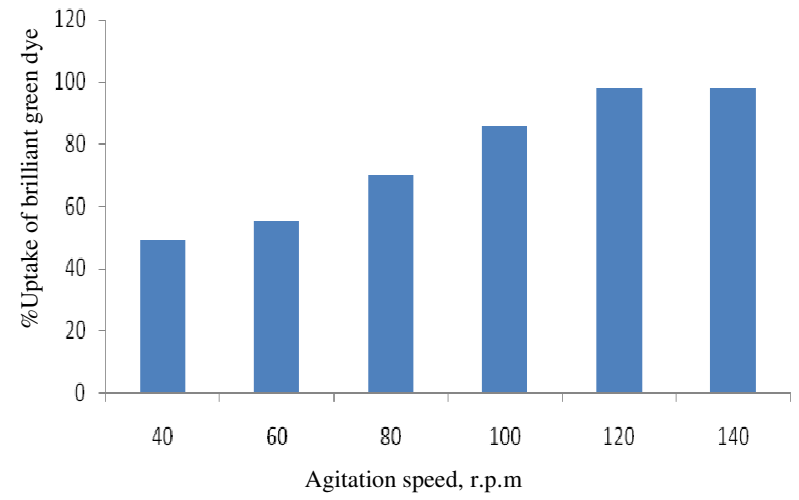

Figure 4. Effect of agitation speed on the \% uptake of the brilliant green by the polymer

\section{Effect of amount of polymer}

The amount of the $\beta$-CD polymer is another important parameter that affects \%uptake of dye. A quantitative removal $(\geq 95 \%)$ cannot be achieved when the $\beta$-CD polymer is less than the optimum amount. In order to optimize the smallest amount of polymer, $100 \mathrm{mg}, 200 \mathrm{mg}$, $300 \mathrm{mg}, 400 \mathrm{mg}$ and $500 \mathrm{mg}$ of the polymer were added to the solution containing known amount of dye. The quantitative recoveries were obtained at $200 \mathrm{mg}$ of $\beta$-CD shown in (Figure 5). Therefore, $200 \mathrm{mg}$ of the $\beta$-CD has been used for further studies.

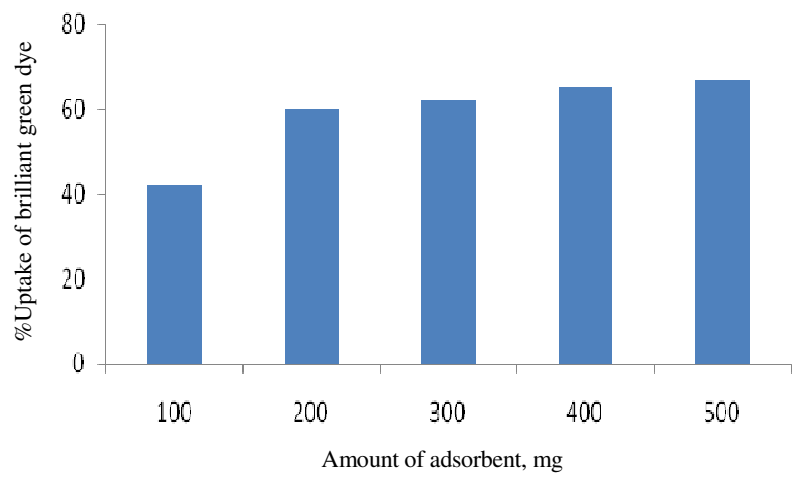

Figure 5. Effect of amount of adsorbent on the \% uptake of the brilliant green by the polymer

\section{Applications}

\section{Determination of samples}

The proposed method has been applied for the determination of brilliant green dye in mouth freshener and jelly. The results are given in table. 
Table 1. Result of determination of brilliant green in food samples

\begin{tabular}{cccc}
\hline Food samples & Added, $\mu \mathrm{g} / \mathrm{mL}$ & Found, $\mu \mathrm{g} / \mathrm{mL}$ & Recovery, \% \\
\hline${ }^{\mathrm{a}}$ Pizzle mouth freshener & 0 & 0.012 & - \\
& 0.536 & $0 . .524$ & 97.76 \\
& 1.072 & 1.064 & 99.25 \\
${ }^{\mathrm{b}}$ Jelly & 0 & 0.025 & - \\
& 0.536 & 0.522 & 97.38 \\
& 1.072 & 1.038 & 99.19 \\
\hline
\end{tabular}

${ }^{a}$ Pizzle mouth Freshener - locally available in market, ${ }^{b}$ Jelly - locally available in market

\section{Conclusion}

The proposed preconcentration method consist of a simple and low procedure which permits the quantitative recovery of brilliant green dye from food samples. The synthesis of the polymer is easy and the method has a good accuracy, sensitivity and repeatability. The polymer has been used in all the experiments performed for the study. It has a unique stability and reusability. This method is convenient for the determination of brilliant green dye.

\section{References}

1. Mane V S, Mall I D and Srivastava V C, Dyes and Pigments, 2007, 73(3), 269-278.

2. $\quad$ Mane V S and Vijay Babu P V, Desalination, 2011, 273, 321-329.

3. McKay G, Otterburn M S and Aga D A, Water Air Soil Pollut., 1985, 24(3), 307-322.

4. $\quad$ Dutta P K, Indian J Environ Protect., 1994, 14(6), 443-446.

5. Gregory A R, Elliot S and Kluge P, J Appl Toxicol., 1991, 1(6), 308-313.

6. Gandhi J, Dangi R, Sharma J C, Verma N and Bhardwaj S, Der Chem Sinica, 2010, 1(3), 77-83

7. Parwate D V and Mankar S S, E-J Chem., 2011, 8(2), 680-684.

8. Venkat S M and Babu P V V, Inst of Tech Nirma Uni Ahme International Conference NUiCONE- 2011.

9. $\quad$ Li R, Jiang Z T and Liu Y H, J Food Drug Anal., 2008, 16(5), 91-96.

10. Velic D, Knapp M and Kohler G, J Mole Stucture, 2001, 598(1), 49-56.

11. Abay I, Denizli A, Biskin E and Salih B, Chemosphere, 2005, 61(9), 1263-1272.

12. Shao D, Sheng G, Chen C, Wang X and Nagastu M, Chemosphere, 2010, 79(7), 679-685.

13. Wu M and Zhu X, Spectrochim Acta A Mol Biomol Spectrosc., 2010, 77(5), 1021-1024.

14. Bhaskar M, Aruna P, Rama Jeevan, Ganesh Jeevan and Radhakrishnan G, Anal Chim Acta, 2004, 509(1), 39-45. 